\title{
A comprehensive review of the impact of transmission technologies on the electrical grid
}

\author{
Una revisión exhaustiva del impacto de las tecnologías de transmisión en la red eléctrica
}

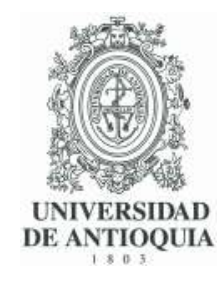

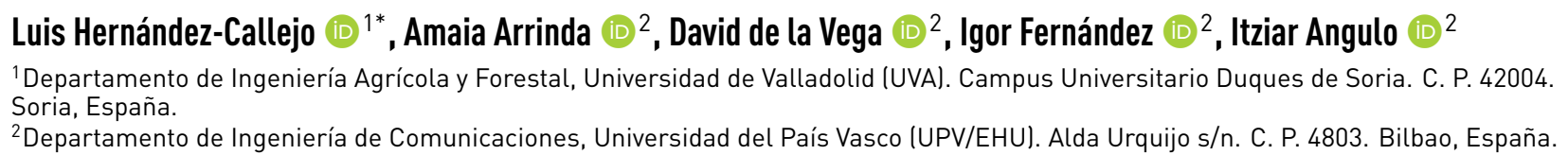

\section{CITE THIS ARTICLE AS:}

L. Hernández, A. Arrinda, D. de la Vega, I. Fernández and I. Angulo "A Comprehensive Review of The impact of transmission technologies on the electrical grid", Revista Facultad de Ingeniería Universidad de Antioquia, no. 93, pp. 82-91, Oct-Dec 2019. [Online]. Available: https://www . doi.org/10.17533/ udea.redin. 20190515

\section{ARTICLE INFO:}

Received: November 20, 2018

Accepted: May 17, 2019

Available online: May 17, 2019

\section{KEYWORDS:}

Smart grid, wireless communications, grid automation

redes eléctricas inteligentes, comunicaciones inalámbricas, automatización de red

\begin{abstract}
The electrical infrastructure needs the integration of communication technologies, and in recent decades the progress has been significant. Therefore, this work presents the latest advances in this subject, as well as new functionalities. The work brings together the advances in automation, from the early stages to the present day. At the moment, the Smart Grid needs to use communication technologies to enable a response to demand, which will allow a different relationship between customer and company. The work presents the existing network architectures and communication protocols used in the Smart Grid. The document presents the challenges of electrical infrastructure, and shows the benefits and drawbacks of different communication technologies. In summary, the paper shows the parallel evolution of the communication technologies and the electrical grid, as a basic aspect for the development of new functionalities and services for all the agents involved in the power generation-transmission-distribution system.
\end{abstract}

RESUMEN: La infraestructura eléctrica necesita la integración de tecnologías de comunicación, y en las últimas décadas el progreso ha sido significativo. Por lo tanto, este trabajo presenta los últimos avances en este tema, así como las nuevas funcionalidades. El trabajo reúne los avances en automatización, desde las primeras etapas hasta la actualidad. En este momento, Smart Grid necesita utilizar tecnologías de comunicación para permitir una respuesta a la demanda, lo que permitirá una relación diferente entre el cliente y la empresa. El trabajo presenta las arquitecturas de red existentes y los protocolos de comunicación utilizados en la red inteligente. El documento presenta los desafíos de la infraestructura eléctrica y muestra los beneficios e inconvenientes de las diferentes tecnologías de comunicación. En resumen, el documento muestra la evolución paralela de las tecnologías de comunicación y la red eléctrica, como un aspecto básico para el desarrollo de nuevas funcionalidades y servicios para todos los agentes involucrados en el sistema de generación-transmisión-distribución de energía.

\section{Introduction}

The centralized generation is evolving into a distributed system. In addition, the electrical infrastructure is radial but it evolves meshed or star. This requires an evolution in the electrical system, and the one-way

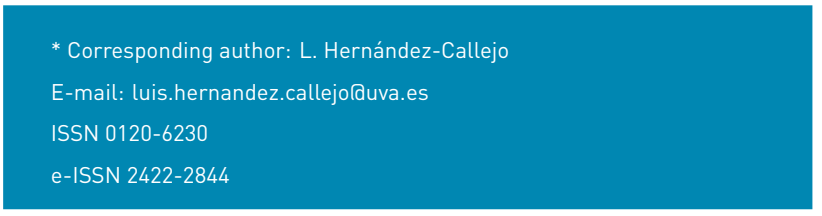

generation-transport-distribution scheme must be changed to a distributed model.

The utility and the customer are starting to relate differently, and it is mainly due to the Smart Grid and its functionalities as the answer to the demand. In this new scenario, the user will be an active actor, since for example, he will be able to generate power. This allows generating a distributed generation model, and the customers will be prosumers (consumers and producers). Therefore, the systems must be more flexible 
and guarantee a more reliable and robust electrical infrastructure.

This scenario would not be possible without the use of an advanced communications system that provides all the high-demanding requirements described in the previous sentences [1-4].

The present paper is an extension of the review displayed in the Iberoamerican Congress of Smart Cities (ICSC-CITIES 2018) [5].

\section{Automation and control of the electrical grid: historical evolution}

The proper performance of the electrical infrastructure is a critical factor, because power cuts cause serious economic, social and technical consequences [6]. Due to the expected radical changes in social, economic and demographic areas, the infrastructures of the cities require a radical change [7]. Due to the higher dependence on the electricity, and considering the new functionalities that are being proposed for the city of the future (Smart City), the electric network infrastructure is a substantial and fundamental part of this process.

The modernization of the electrical infrastructure has not happened overnight. In the 1950s, analog communications were employed to collect real-time data of power outputs from power plants, and tie-line flows to power companies. To achieve this, operators used analog computers to conduct Load Frequency Control and Economic Dispatch [8]. Load Frequency Control was used to control generation in order to maintain frequency and interchange schedules between control areas, and Economic Dispatch adjusts power outputs of generators at an equal incremental cost.

It is from 1960, with the advent of digital computing, when the Remote Terminal Units were developed, which were designed to collect voltage measurements, active and reactive power, and states of protection devices in substations. To make this measure possible, the use of dedicated transmission channels was necessary to interconnect the final devices with the computational center. As a consequence of the blackout of 1965 in the USA, more extensive use of digital computers was highly recommended, in order to improve the real-time operations of the interconnected power systems. The use of computers and digital systems considerably increased from 1970, with the introduction of the concept of system security, covering both generation and transmission systems [9].
The first control centers were based on dedicated computers, but in the subsequent years, they were gradually replaced by general-purpose computers. It is already from 1980 when the microcomputers were replaced by UNIX workstations, interconnected by means of Local Area Networks (LAN) [10]. These first networks of interconnected computers allowed more rapid and efficient data exchange between different parts of the electrical grid.

The real revolution in the electrical system took place in the second half of the 1990s, when the electrical industry launched the reorganization of the system. Since then, services ceased to be vertical and the generation, the transport and the distribution of the energy were separated. In addition, monopolies were replaced by competitive markets [11]. The combination of these both aspects marked a turning point in the evolution of the electrical system. In this new scenario, three clearly differentiated segments were created in the electrical system: Energy Management System, Business Management System and Market. The interaction between these segments is shown in Figure 1. The figure shows the three basic levels in the electrical system: energy management system, business management system and market. Some of the components of the energy management system are: SCADA, State Estimation, Contingency, Unit Commitment and Load Management. Some of the components of the business management system are: Forecasting, Schedules, Billing, Real-Time Dispatch, Settlement. Some of the components of the market are: Wholesaler, Retail and Users.

\section{The development of Smart Grids}

The concept of Smart Grid is based on systems that are able to manage the generation, distribution and consumption of the electricity in a more efficient manner, as they include techniques to measure and predict the consumption (demand), and consequently, adopt the necessary generation and distribution resources (offer), with the required security levels. Therefore, the Smart Grids will allow a real scenario of distributed renewable generation, automatized distribution and controlled storage of the energy at different levels, based on real-time updated data from all the elements connected to the grid, smart analysis and automated decisions, in order to achieve a more rapid and precise control of the whole grid. This deep analysis requires a high number of sensors spread all over the grid transmitting information about signal quality, generation and consumption data and state of the grid [1].

The final objectives of the Smart Grids are, among others, the quality of the power supply, in a more robust, efficient, 


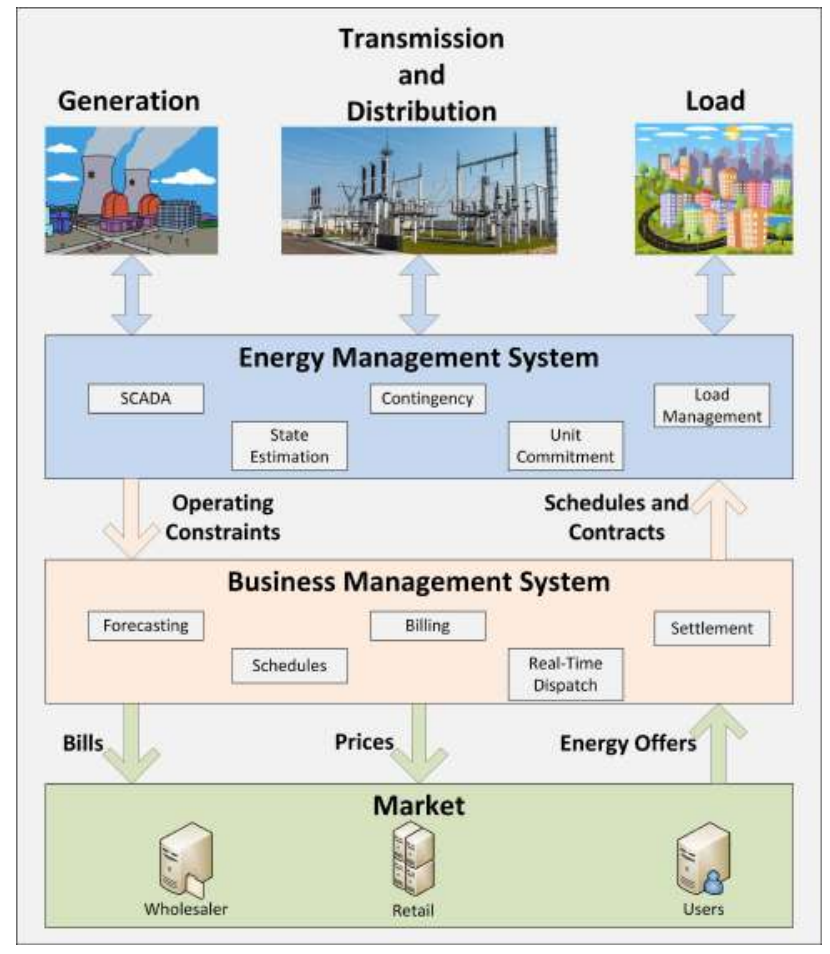

Figure 1 Segments of the electrical system and interaction between them

reliable and resilient network, and better-balanced demand response.

\subsection{Use cases in the development of Smart Grids}

As it is known, renewable production is uncertain and variable due to weather conditions. In addition, a more distributed renewable production is being promoted, even to a prosumer (producer and consumer) level. The optimization of renewable production relies on the development of efficient, distributed and competitive storage systems.

Additionally, in the consumer side, smart meters located at homes are evolving towards shorter measurement intervals and they will reach near real-time monitoring in the next future, which implies a huge increase of this type of data from a great number of users. In the distribution grid side, a great number of sensors is expected to be installed in the low and medium voltage infrastructures, in order to obtain objective values that allow the evaluation of the state of the grid. The combination of both aspects will demand a significantly higher data rate from communications technology. Accordingly, some representative use cases of the next development of Smart Grids are the following [12]:

- Self-healing networks: grid networks with capabilities for ultra-fast fault location, isolation and power restoration. Though self-healing networks is a wide topic that covers many different features, a quasi-immediate response to fault situation requires communication processes between protective devices with ultra-low latencies, which enable that the grid topology during the fault time is rapidly restructured. Additionally, nearby distributed generation should be disconnected so that they do not feed fault current, while more distant generation units should remain connected.

- Integration of Distributed Energy Resources (DERs): the system reliability through protective messages must be guaranteed, in order to avoid system overload. Microgrids are of particular interest in the control of the network, as they enable the integration of DERs at a community/customer level; their management and regular operation require extensive and low latency message signaling.

- The real-time and accurate balance between generation and consumption: this balance is based on accurate forecasting algorithms of both consumer consumption and renewable generation. Real-time communications will allow the data exchange for obtaining an accurate balance, as medium and long-term consumption profiles and generation estimations are not enough for a real-time balance. The data of power consumption and generation are obtained from the deployment of an Advanced Metering Infrastructure (AMI), composed of a set of Smart Metering devices located at each home or company that transmit automatic periodical reading of consumption/generation information.

- The integration of the electric vehicle into the power grid requires near real-time communications between the energy infrastructure, the charging stations and the electric vehicles, in order to optimize the resources of the grid and the storage capacity of the vehicles.

All the previous development scenarios and new applications will require new electrical equipment, but also a renewed monitoring and control systems for electricity distribution networks, which must be based on the real-time exchange of measurements data between the generation, storage and consumption elements of the electrical grid. 


\section{The role of the communications in the development of the Smart Grids}

This section includes an outline of the wired and wireless transmission technologies used in the electric grid. In order to categorize the use of these technologies, the areas of the electrical infrastructure that should be considered for the application of the communication systems are defined in advance. Last, the evolution of communication systems in the Smart Grid is summarized, in order to provide the basis and the tendencies for the next stages of the evolution of the communication technologies for the Smart Grids.

\subsection{The communication systems in the structure of the electrical grid}

The performance of the communication technology may vary depending on the conditions of the grid, such as the grid topology, the density of communication devices (users, data concentrators or substations) to be connected, the distance between them and the requirements of the communications (data rate, robustness, priority levels), and the presence of interfering electrical noise sources $[13,14]$. For example, high-speed communications can be used for the connection of electrical substations in urban areas; however, this solution may not be feasible in other areas, such as rural environments or remote devices.

Accordingly, the network infrastructure can be separated into two zones $[15,16]$ :

- Last mile connectivity: it can be understood as the high-speed communications between the substations and the control center. There are wired communications (PLC and fiber optic) and wireless communications (via satellite and wireless in general).

- High-speed communication core network: this network can be private or public. A high-speed network for the automation of substations is Internet based on Virtual Private Network.

\subsection{Wired and wireless transmission technologies}

The most common wired and wireless are compared in Table (1).

Power line communications (PLC) is a transmission technology that uses the electrical grid for data transmission. An immediate advantage is a fact that the transmission infrastructure is easy to install, leading to savings in deployment time and costs. For this reason, it has been massively deployed for Advanced Smart Metering services in some European countries [17].

On the opposite side, neither the power cables nor the electrical grid topology was designed for data transmission, and they present severe drawbacks such as high transmission losses and high latency values, which lead to low data rates and very low redundancy for transmission data. Recent studies [13, 14, 18-21] have demonstrated that a detailed characterization of the electrical grid as a transmission medium is needed for a better understanding of the real possibilities of using PLC for advanced applications.

Though PLC transmission technologies have objective limitations when compared to wireless technologies, they can be the best option in two particular situations: first, when the control of the transmitted data is a strategic issue for the utility; and second, when the coverage of the wireless technologies is limited, such as low-density inhabited areas or devices located in subterranean rooms.

The most successful transmission technologies for Advanced Smart Reading services based on PLC are PRIME [22-24], Meters \& More and G3-PLC [25].

The alternative to Power Line Communications (PLC) is the use of wireless technologies for connecting both Smart Meters in the homes and wireless sensor networks all along the electrical grid for monitoring and automation tasks $[29,30]$. The main benefits of the use of wireless networks are:

- The sensor network provides capabilities for self-configuration and automatic routing of the data transmission.

- The coverage of a sensor is low, but the entire network of sensors may form a wide area communications network.

- Redundancy for transmission data is easy to achieve, due to the collaboration and the automatic reconfiguration of all the sensors.

- The sensors are usually reliable, relatively cheap, self-configurable, and robust against adverse climatic conditions.

- The network has low installation and maintenance costs.

On smart metering applications, cellular technologies, such as GPRS (General Packet Radio Service), 36 (third generation of mobile communications) or LTE (Long Term Evolution or fourth generation 4G), are a good option for the communication link between the data concentrator 
Table 1 Advantages and disadvantages of most common communication technologies used in the Smart Grids

\begin{tabular}{|c|c|c|}
\hline Communication technology & Advantages & Disadvantages \\
\hline PLC & $\begin{array}{l}\text { - Wide coverage, due to the existence } \\
\text { of already deployed power lines } \\
\text { (distribution and transport). } \\
\text { - Investment in infrastructure is more } \\
\text { economical. }\end{array}$ & $\begin{array}{l}\text { - Electric cables conduct noise } \\
\text { and interferences, which degrade } \\
\text { communications }[26,27] \text {. } \\
\text { - As the power line is a shared } \\
\text { medium, the data rate per user is } \\
\text { lower than the nominal capacity, } \\
\text { depending on the number of users } \\
\text { simultaneously transmitting. } \\
\text { - The switches, inverters and other } \\
\text { protection devices degrade the } \\
\text { quality of PLC, [28]. } \\
\text { - The impedance varies with time, } \\
\text { network topology and devices } \\
\text { connected at each moment, which } \\
\text { causes that the attenuation and } \\
\text { distortion of the signal are high and } \\
\text { changing. } \\
\text { - Power cables are not twisted } \\
\text { and use no shielding, which may } \\
\text { cause significant Electro Magnetic } \\
\text { Interference (EMI) }\end{array}$ \\
\hline
\end{tabular}

- It provides high bandwidth, required by applications such as electrical automation.

Optical fiber communication

- There is no EMC problem.

- Immune to interferences from external sources.
- The cost of devices and installation is more expensive.
Wireless communication
- Wireless communication is quick to install.

- In case of cellular network, the cost of infrastructure is low, since the existing infrastructure can be used.
- IEEE 802.11b presents the limitation of coverage $(100 \mathrm{~m})$, although other technologies such as WiMAX do not have this limitation.

- However, technologies such as WiMAX can have the drawback of the absence of infrastructure in remote areas.

- Cellular technologies IGPRS, 3G or LTE) provide wide coverage, lower latency and great capacity. They represent the main alternative technology to PLC.

and the utility data center [1]. The main advantage of these technologies is that cellular networks are already 
deployed, which provides a simple and inexpensive solution for the deployment of services [31, 32].

Within $3 G$ technologies, several standards for data transmission were developed: UMTS, CDMA2000 and EDGE, among others. As this technology is already deployed at a large scale, it can be considered as a mature and stable option, providing a wide coverage in

most regions and data rates of at least $0.2 \mathrm{Mbps}$. These characteristics position these technologies as a very good option for the communication link between the data concentrator and the utility data center.

The Long Term Evolution (LTE) technology is the evolution of the GSM/UMTS standards for high-speed mobile communications, providing reduced latency, higher capacity and lower power consumption [33]. In the Smart Grid applications, LTE can be used as the transmission technology of the Advanced Metering Infrastructure backhaul network, and in particular, the communication link between the data concentrator and the utility control center.

\subsection{Evolution of the communication systems in the electrical infrastructure}

One of the aspects that enable and foster the great evolution of the electrical system described in the previous section was the development of a robust communications layer. The communication systems used in the electrical infrastructure have also undergone great changes, in order to provide new functionalities adapted to both the evolution of the grid and to the new requirements of the companies in charge of the transmission and distribution services.

Regarding Power Line Communications, the high number of interferences and noise sources, together with the high variability with time and frequency, represent a great challenge for the proper performance of the data transmission.

The strong points for the use of wireless communications have been the higher flexibility, the better conditions of the propagation medium and the potential use of transmission technologies already tested. On the weak side, the difficulties to provide complete coverage and the need of deploying the complete transmission-reception chain for each link. Nevertheless, these drawbacks were recently overcome by the use of advanced cellular technologies, such as GPRS and LTE, which provide good rates of coverage, availability, data rate and latency. Future Smart
Grids functionalities and applications rely on the better performance of wireless technologies, mainly LTE and $5 G$.

The historical evolution of wired and wireless communications in the electricity grid is shown in Table (2) $[12,28]$.

\section{What is next?}

This section presents some of the recently developed lor foreseen for the next years) communications technologies that can be potentially applied to the Smart Grids, and therefore, the basis for the development of new functionalities. As these technologies must satisfy the requirements of new functionalities of the Smart Grids, the requirements of the future electrical grid are also outlined.

\subsection{Requirements of the future electrical grid}

The future of Smart Grids relies on a wide communication infrastructure that must provide fast, reliable and flexible communications to a user-centric and distributed energy grid, with new services and very high-demanding requirements.

One of the key requirements is latency. A more reliable and resilient grid, with increased robustness to power outages and recovery to faults in less than $100 \mathrm{~ms}$, will be an essential requirement of the electrical grid in the incoming years.

The capacity for managing thousands of new devices connected to small areas of the electrical grid, all of them transmitting and/or receiving data will be another significant requirement. These devices may be small sensors transmitting data about the state of the distribution grid, the quality of the service, real-time data of consumption or generation from consumers and prosumers, or data related to the performance of the devices connected to the distribution grid.

The previous issue leads to data rates in the order of Megabytes per second in a wide section of the grid, and even of Gigabytes per second in dense areas and in the backbone sections. When this aspect is combined with latency values of the order of a few milliseconds, the challenge to be addressed by the communication technology is noteworthy.

The availability of the communications devices connected to the grid is another important requirement in a real-time monitoring and management network. Hence, availability above $99.999 \%$ will be demanded (which implies disconnection periods shorter than 5 minutes per yearl. 
Table 2 Evolution of the communication systems in the electrical infrastructure

\begin{tabular}{|c|c|c|c|c|}
\hline Year & Achievement & Network architecture & $\begin{array}{l}\text { Communication } \\
\text { protocols and standards }\end{array}$ & Communication media \\
\hline $\begin{array}{l}\text { Before } \\
1985\end{array}$ & $\begin{array}{l}\text { Without } \\
\text { standardization }\end{array}$ & $\begin{array}{l}\text { Isolated substations } \\
\text { Hierarchical tree } \\
\text { Single master }\end{array}$ & $\begin{array}{l}\text { Conitel } 2020 \\
\text { ModBus } \\
\text { SEL } \\
\text { WISP }\end{array}$ & $\begin{array}{l}\text { RS232 } \\
\text { RS485 } \\
\text { Power-line carrier } \\
\text { Dial Up } \\
\text { Trunked Radio } \\
\text { Speed below } 1200 \text { bps }\end{array}$ \\
\hline $\begin{array}{l}1985- \\
1995\end{array}$ & $\begin{array}{l}\text { Standardization } \\
\text { begins }\end{array}$ & $\begin{array}{l}\text { Redundant links } \\
\text { Hierarchical tree } \\
\text { Multiple master }\end{array}$ & $\begin{array}{l}\text { TASE } 2 \\
\text { IEC } 60870 \\
\text { DNP3 Serial }\end{array}$ & $\begin{array}{l}\text { Packet Radio } \\
\text { Leased lines } \\
\text { Speed between } 9600 \\
\text { and } 19200 \text { bps }\end{array}$ \\
\hline $\begin{array}{l}1995- \\
2000\end{array}$ & $\begin{array}{l}\text { Local Area } \\
\text { Network (LAN) } \\
\text { and Wide Area } \\
\text { Network (WAN) }\end{array}$ & $\begin{array}{l}\text { Substations with peer-to-peer } \\
\text { communications } \\
\text { Interconnected substations via WAN }\end{array}$ & $\begin{array}{l}\text { TCP-IP } \\
\text { Telnet } \\
\text { HTTP } \\
\text { FTP } \\
\text { DNP3 WAN/LAN }\end{array}$ & $\begin{array}{l}\text { Ethernet } \\
\text { Spread Spectrum Radio } \\
\text { Frame Relay } \\
\text { Megabit Data Rates }\end{array}$ \\
\hline $\begin{array}{l}2000 \text { to } \\
\text { present }\end{array}$ & $\begin{array}{l}\text { Integration within } \\
\text { the business }\end{array}$ & $\begin{array}{l}\text { Use of Internet } \\
\text { Utility connection with the business } \\
\text { network } \\
\text { Extension of the network to customer } \\
\text { premises }\end{array}$ & $\begin{array}{l}\text { TCP-IP } \\
\text { IEC } 61850 \\
\text { XML } \\
\text { Power Line } \\
\text { Communication (PLC) }\end{array}$ & $\begin{array}{l}\text { Digital Cellular } \\
\text { IP Radios } \\
\text { Wireless Ethernet } \\
\text { Gigabit backbones }\end{array}$ \\
\hline
\end{tabular}

\subsection{New communication technologies}

The first global technology that will address all the above-mentioned challenges is the wireless technology $5 \mathrm{G}$ (fifth generation), the next step in the evolution of mobile communications. The improvements of this technology are focused on enhanced capacity, throughput, latency, spectrum efficiency and energy consumption [33].

After several research projects and test beds, standardization is currently in the process [29-33]. The development of $5 G$ is aligned to the performance requirements defined by the International Telecommunications Union (ITU) for an IMT-2020 technology, outlined in the Report ITU-R M.2412 [32, 33]. IMT stands for International Mobile Telecommunications, the term used by the ITU to describe generations of radio interface standards for mobile systems. IMT-2020 calls for support for enhanced mobile broadband (eMBB) and for new use cases that require massive machine-type communications (mMTC) and ultra-reliable and low latency communications (URLLC) [31].

The evolution with respect to the previous technology is shown in Figure 2:

Several use cases can be defined, from loT applications for a huge number of low-cost sensors to ultra-reliable low latency communication, with varying throughput requirements [26]. Hence, $5 G$ is envisioned as the unique technology able to address the wide variety of cases in the energy sector, as it will allow the deployment of specific

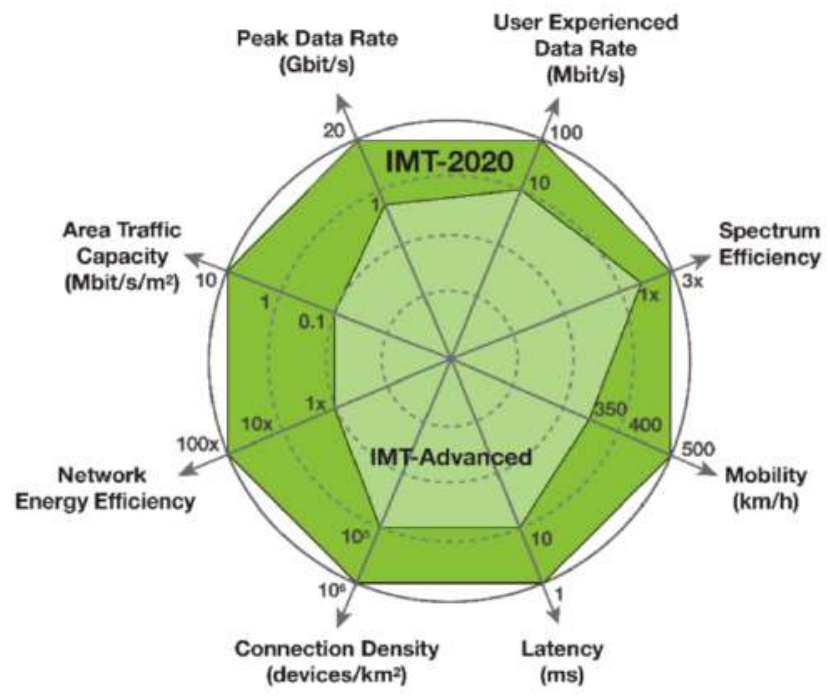

Figure 2 Performance of $5 G$ technology with respect to the previous generation (4G) [11]

virtual network functions (this is, dedicated networks for different applications, named 'network slices') that ensure dedicated technical performances, such as a constant latency for a specific sector/domain [12]. The network slicing and the mobile edge computing (distributed computing and storage capabilities) will enable the distributed data transmission and the processing capabilities that are required by the energy use case [12]. Therefore, the technical requirements of the network slices will be determined by the requirements of the new services and the particularities of the scenario 
Table 3 Requirements for $5 G$ for different sections of the electrical grid

\begin{tabular}{|c|c|c|}
\hline Section of the electrical grid & Description/Needs & Technical requirements for $5 \mathrm{G}$ \\
\hline $\begin{array}{c}\text { Communication network for } \\
\text { electrical grid access }\end{array}$ & $\begin{array}{l}\text { Communicating endpoints in the LV section } \\
\text { (i.e. Smart Meters, secondary substations). } \\
\text { This means: } \\
\text { - The typical diameter of the covered } \\
\text { region < } 10 \mathrm{~km} \\
\text { - Applications in this area are typically } \\
\text { less critical } \\
\text { - The low capability required, except for } \\
\text { some particular endpoints due to grid } \\
\text { stability of load or generation } \\
\text { - TCP-based communication is } \\
\text { dominant }\end{array}$ & $\begin{array}{l}\text { - Bandwidth: } 1 \text { kbps per home } \\
\text { - End-to-end Latency (upper bound): < } \\
1 \mathrm{~s} \text { from the data control center or } \\
\text { secondary substation to the Smart } \\
\text { Meters } \\
\text { - Packet-loss: no specific requirement } \\
\text { - Availability: } 99 \% \quad 190 \mathrm{~h} / \text { year } \\
\text { downtime) } \\
\text { - Failure convergence time: < } 1 \mathrm{~s} \\
\text { - Handling of crisis situations: not } \\
\text { required }\end{array}$ \\
\hline $\begin{array}{c}\text { Communication network for } \\
\text { electrical grid backhaul }\end{array}$ & $\begin{array}{l}\text { Communicating endpoints in the MV } \\
\text { section (i.e. secondary substations). This } \\
\text { means: } \\
\text { - The typical diameter of the covered } \\
\text { region is < } 100 \mathrm{~km} \text {. } \\
\text { - Critical applications such as } \\
\text { automating fault detection and } \\
\text { protection. } \\
\text { - Stable, reliable and real-time } \\
\text { communications are required } \\
\text { between substations and towards the } \\
\text { control center }\end{array}$ & $\begin{array}{l}\text { - Bandwidth: several Mbps per link } \\
\text { - End-to-end Latency (upper bound): } \\
<50 \mathrm{~ms} \text { between secondary } \\
\text { substations and towards the control } \\
\text { center } \\
\text { - Packet-loss: < } 10-6 \text { plus } \\
\text { unacknowledged information } \\
\text { - Availability: } 99.99 \% \text { (50 min/year } \\
\text { downtime) } \\
\text { - Failure convergence time: }<1 \mathrm{~s} \\
\text { - Handling of crisis situations: } \\
\text { recovering from medium power } \\
\text { down-times on a large scale } \\
\text { mandatory }\end{array}$ \\
\hline $\begin{array}{l}\text { Communication network for } \\
\text { electrical grid backbone }\end{array}$ & $\begin{array}{l}\text { Communicating endpoints in the HV } \\
\text { section (i.e. primary substations). This } \\
\text { means: } \\
\text { - Typ. the diameter of the covered } \\
\text { region is < } 1000 \mathrm{~km} \\
\text { - Critical applications such as } \\
\text { protection functions } \\
\text { - Ultra stable, reliable and real-time } \\
\text { communications are required } \\
\text { between substations and towards the } \\
\text { control center } \\
\text { - Currently, dedicated optical fiber } \\
\text { links }\end{array}$ & $\begin{array}{l}\text { - Bandwidth: several Mbps to Gbps per } \\
\text { link } \\
\text { - End-to-end Latency (upper bound): } \\
<5 \text { ms between primary substations } \\
\text { and towards the control center } \\
\text { - Packet-loss: < } 10-9 \text { plus } \\
\text { unacknowledged information } \\
\text { - Availability: } 99.999 \% \text { (5 min/year } \\
\text { downtime) } \\
\text { - Failure convergence time: seamless } \\
\text { failover required (no loss of } \\
\text { information) } \\
\text { - Handling of crisis situations: } \\
\text { recovering from long power } \\
\text { down-times on a large scale } \\
\text { mandatory }\end{array}$ \\
\hline
\end{tabular}

where it is applied (specific section of the grid MV/LV, the geographical distribution of the users, type and priority level of the data, etc.). Table 3 summarizes these requirements, as a function of the section of the network that is considered $[12,33]$. 


\section{Conclusions}

An essential feature in the evolution of the Smart Grids is the use of information and communications technology to gather different types of data from a distributed network of sensors and take fast decisions according to the analysis of this information. The final purpose is the improvement of the efficiency, reliability, economics, and sustainability of the production, transmission, and distribution of electricity.

The conversion of the user from a consumer to a prosumer, together with the new generated distribution systems, will change completely the architecture and the procedures to manage the electrical grid. This will lead to employing two-way communication systems in the smart grid.

In parallel, the recent developments on the wireless technologies, mainly in cellular systems, providing higher data rates, much lower latency values and the possibility to provide simultaneous service to a high number of devices, will open the door to innovative services for the users and the rest of the agents related to the electrical grid.

Considering the very high-demanding requirements of the future services and use cases the Smart Grids, 5G is a very flexible technology that can support efficiently, within a unified infrastructure, the high demanding requirements of all the new services outlined in the previous sections for the electrical grid. This transmission technology will provide improved performance in the last mile connectivity; moreover, for those applications based on strict latency requirements, $5 G$ could replace some optic fiber links in LV and MV sections, in order to unify the transmission technology. Efficient integration of the $5 G$ access technologies includes multi-connectivity approaches where the user equipment is simultaneously connected to several access technologies or frequency bands, which could help to address the requirements in terms of crisis situation handling.

The $5 G$ technology can be particularly interesting for those areas where PLC has not been deployed.

\section{Acknowledgments}

The authors thank the CYTED Thematic Network “Ciudades Inteligentes Totalmente Integrables, Eficientes y Sostenibles (CITIES)" n 518RT0558.

This work has been financially supported in part by the Basque Government (Elkartek program).

\section{References}

[1] N. Andreadou, M. Olariaga, and G. Fulli. (2016, May 17) Telecommunication technologies for smart grid projects with focus on smart metering applications. [Online]. Available: https://doi.org/10.3390/en9050375

[2] N. Uribe, L. Hernández, D. D. la Vega, and I. Angulo. (2016, February 29) State of the art and trends review of smart metering in electricity grids. [Online]. Available: https://doi.org/10.3390/app6030068

[3] J. A. Cortés and J. M. Idiago. (2018) Smart metering systems based on power line communications. [Springer Link]. [Online]. [Online]. Available: https://doi.org/10.1007/978-981-13-1768-2_4

[4] K. Sharma and L. MohanSaini. (2017, January) Power-line communications for smart grid: Progress, challenges, opportunities and status. [Online]. Available: https://doi.org/10.1016/j.rser.2016. 09.019

[5] L. Hernández, A. Arrinda, D. de la Vega, I. Fernández, and I. Angulo, "The impact of transmission technologies on the evolution of the electrical grid," ICSC-CITIES 2018. Communications in Computer and Information Science, Cham, Suiza, 2019.

[6] B. Clinton. (1996, Jul. 17) Executive order 13010-critical infrastructure protection. [Online]. Available: https://www.hsdl. org/?view\&did=1613

[7] L. Lugaric, S. Krajcar, and Z. Simic, "Smart city - platform for emergent phenomena power system testbed simulator," in 2010 IEEE PES Innovative Smart Grid Technologies Conference Europe (ISGT Europel, Oct. 2010, pp. 1-7.

[8] T. E. D. Liacco. (2002, October) Control centers are here to stay. [Online]. Available: https://doi.org/10.1109/MCAP.2002.1046107

[9] F. F. Wu. (1988, April) Real-time network security monitoring, assessment and optimization. [Online]. Available: https://doi.org/ 10.1016/0142-0615(88)90020-8

[10] T. E. D. Liacco. (1994, October) Modern control centers and computer networking. [Online]. Available: https://doi.org/10.1109/67.318916

[11] P. L. Joskow, "Restructuring, competition and regulatory reform in the u.s. electricity sector," The Journal of Economic Perspectives, vol. 11, no. 3, pp. 119-138, 1997.

[12] $5 G$ Infrastructure Association, " $5 \mathrm{~g}$ and energy," $5 \mathrm{G}$ Infrastructure Association, Gaston Crommenlaan, Belgium, Tech. Rep. Version 1.0, Sep. 2015.

[13] N. Uribe and et al. (2016, November 30) Study of unwanted emissions in the cenelec-a band generated by distributed energy resources and their influence over narrow band power line communications. [Online]. Available: https://doi.org/10.3390/en9121007

[14] I. Fernandez and et al. (2019, February) Characterization of non-intentional emissions from distributed energy resources up to $500 \mathrm{khz}$ : A case study in spain. [Online]. Available: https: //doi.org/10.1016/j.ijepes.2018.08.048

[15] A. Sendin, I. Peña, and P. Angueira, "Strategies for power line communications smart metering network deployment," Energies, pp. 2377-2420, 2014.

[16] N. K. Tan, Building VPNs: With IPSec and MPLS. McGraw-Hill Networking, 2003.

[17] Prospex Research, “Europe's top twenty power industry players 2016e," Prospex Research Ltd, Tech. Rep., Jun. 2016.

[18] Investigation Results on Electromagnetic Interference in the frequency range below $150 \mathrm{kHz}$, S.R. CLC/TR 50669:2017, 2017.

[19] Signalling on low-voltage electrical installations in the frequency range $3 \mathrm{kHz}$ to $148,5 \mathrm{kHz}$ - Part 1: General requirements, frequency bands and electromagnetic disturbances, CENELEC - EN 50065-1, 2011.

[20] Specification for radio disturbance and immunity measuring apparatus and methods - Part 2-3: Methods of measurement of disturbances and immunity - Radiated disturbance measurements, CISPR 16-2-3:2016, 2016.

[21] G. López, J. Moreno, E. Sánchez, C. Martínez, and F. Martín. (2017, August 21) Noise sources, effects and countermeasures in narrowband power-line communications networks: A practical approach. [Online]. Available: https://doi.org/10.3390/en10081238

[22] PRIME Alliance Technical Working Group. (2012) Draft specification 
for powerline intelligent metering evolution. PRIME Alliance. [Online]. Available: https://www.prime-alliance.org/wp-content/ uploads/2013/04/PRIME-Spec_v1.3.6.pdf

[23] PRIME Alliance Technical Working Group. (2014) Specification for powerline intelligent metering evolution. PRIME Alliance. [Online]. Available: https://www.prime-alliance.org/wp-content/ uploads/2014/10/PRIME-Spec_v1.4-20141031.pdf

[24] L. da Rocha, L. Monteiro, M. Leme, and S. Stevan. (2018, September 11) Empirical analysis of the communication inindustrial environment based on g3-power linecommunication and influences from electrical grid. [Online]. Available: https://doi.org/10.3390/ electronics7090194

[25] I. Angulo, A. Arrinda, I. Fernández, N. Uribe, I. Arechalde, and L. Hernández, "A review on measurement techniques for non-intentional emissions above $2 \mathrm{khz}$," in 2016 IEEE International Energy Conference (ENERGYCON), April 2016, pp. 1-5.

[26] M. McGranaghan and F. Goodman, "Technical and system requirements for advanced distribution automation," in CIRED 2005 - 18 ${ }^{\text {th }}$ International Conference and Exhibition on Electricity Distribution, June 2005, pp. 1-5.

[27] I. F. Akyildiz, W. Su, Y. Sankarasubramaniam, and E.Cayirci. (2002, March 15] Wireless sensor networks: a survey. [Online]. Available:
https://doi.org/10.1016/S1389-1286(01)00302-4

[28] F.Passerini and A. M. Tonello. (2019, February 13) Smart grid monitoring using power line modems: Anomaly detection and localization. [Online]. Available: https://doi.org/10.1109/TSG.2019. 2899264

[29] F. Covrig and et al., "Smart grid projects outlook 2014," Publications Office of the European Union, Tech. Rep., 2014.

[30] B. Sörries. (2013, sep.) Communication technologies and networks for smart grid and smart metering by cdg 450 connectivity special interest group $(450 \mathrm{sig})$. [Online]. Available: www.cdg.org/resources/files/white_papers/ CDG450SIG_Communicatio\%20_Technologies_Networks_Smart_ Grid_Smart_Metering_SEPT2013.pdf

[31] UMTS Long Term Evolution (LTE) - Technology Introduction, Rohde \& Schwarz, Munich, Germany, 2012.

[32] 5GPPP, “ $5 \mathrm{~g}$ vision. the $5 \mathrm{~g}$ infrastructure public private partnership: the next generation of communication networks and services," The European Commission, Tech. Rep., Feb. 2015.

[33] M. Shafi and et al. (2017, April 07) 5g: A tutorial overview of standards, trials, challenges, deployment, and practice. [Online]. Available: https://doi.org/10.1109/JSAC.2017.2692307 